\title{
Expression of mRNA of chemokines and chemokine receptors and cytokines amount in the blood of healthy volunteers
}

\author{
Kirill Sysoev \\ Federal Center of Molecular Medicine, I.P. Pavlov State Medical University, St.-Petersburg, Russia \\ Email: ksyssoev@mail.ru
}

Received 6 December 2012; revised 7 January 2013; accepted 15 January 2013

\begin{abstract}
Background: Chemokines are small proteins that activate immune system in normal and pathological conditions. The induction of chemotaxis is a well-established role of chemokines. Moreover chemokines are important mediators of angiogenesis, implantation of fetus, and maturation of immune cells. In human body many types of cells express chemokines and cytokines at level of gene and protein. In blood cells chemokine and chemokine receptors mRNA level is a one of crucial points of chemokine system condition. The aim of the study was to evaluate the relationship between plasma concentration of cytokines and chemokines/chemokine receptors mRNA level in blood of healthy volunteers. Results: Gene expression of eotaxin, eotaxin-2, IL-8, MIP-1 $\alpha$, MIP1/, RANTES, CCR1, CCR3, CCR5, CXCR1, and CXCR2 was measured in peripheral blood cells, as well as the concentration of IL-1/, IL-1ra, IL-2, IL-4, IL-5, IL-6, IL-7, IL-8, IL-9, IL-10, IL-12 (p70), IL-13, IL-15, IL-17, eotaxin, FGF-2, G-CSF, GM-CSF, IFN- $\gamma$, IP-10, MCP-1, MIP-1 $\alpha$, MIP-1 $\beta$, PDGF-BB, RANTES, TNF- $\alpha$, and VEGF was evaluated in the plasma of 19 healthy individuals. We studied relationship between mRNA levels of chemokines/recaptors and cytokine concentration in blood of healthy volunteers. Conclusion: These data are allowed to assess chemokines impact in the cytokine regulation of healthy subjects. These results indicate that chemokines and their receptors is diverse and redundant system of immune reactivity in response to internal and external challenges.
\end{abstract}

Keywords: Chemokines; Chemokine Receptors; mRNA; Cytokines; Healthy Volunteers

\section{INTRODUCTION}

Chemokines are peptides, responsible for attracting, mi- gration and interaction of leukocytes. Recently, has been growing interest in the homeostatic functions of chemokines, such as implantation of the embryo, the regulation of signaling pathways and the maintenance of innate immunity. Chemokines acting through specific receptors-GPCR have functional redundancy and overlap own effects. Growth factors, colony-stimulating cytokines, immunoregulatory mediators, together with chemokine provide a complex system of regulation of homeostasis. It seems timely to examine the expression of mRNA chemokine and chemokine receptor cells of the peripheral blood of healthy volunteers, as well as the amount of 27 cytokines (including chemokines) in plasma. The relationship between mRNA expression and amount of biologically active molecules may explain the mechanisms of the physiological state of the human body. Comparison of mRNA expression and production of chemokines in the blood is important for understanding the processes of regulation and activation of the immune system. Thus, mRNA expression does not necessarily mean that the protein synthesized in vivo, will have the full inherent biological activity. $\mathrm{Hu}$ [1] showed that microRNAs are able to stop the broadcast of the matrix protein gene. According to Perry et al. [2] MicroRNA146a suppresses stimulated with IL- $1 \beta$ synthesis of IL-8 and RANTES on the posttranscriptional level. Chemokines and chemokine receptors are a system is to maintain homeostasis in the organ-tissue level. Since the lifetime of chemokines/cytokines, no more than several minutes, and the chemokine receptors undergo rapid internalization is important determination of mRNA these peptides, as this approach allows us to estimate the current capacity of the organism for the synthesis of chemokines/chemokine receptors. Studies on chemokines, mainly conducted on experimental data (animal and cell lines) by modeling the pathological conditions, so there is a distinct lack of research data system chemokines in healthy human population. Chemokines/chemokine receptors have effects against both innate and acquired 
immunity. The present study we believe characterizes chemokines as the substance responsible more for innate immunity, and therefore may contribute to the growth of interest in the study of the role of innate immunity in the regulation of the human body.

\section{MATERIALS AND METHODS}

In this study, we evaluated mRNA eotaxin, eotaxin-2, IL-8, MIP-1 $\alpha$, MIP-1 $\beta$, RANTES, CCR1, CCR3, CCR5, CXCR1 and CXCR2 in peripheral blood, in addition, we determined the concentration of IL- $1 \beta$, IL-1ra, IL-2, IL-4, IL-5, IL-6, IL-7, IL-8, IL-9, IL-10, IL-12 (p70), IL-13, IL-15, IL-17, eotaxin, FGF-2, G-CSF, GM-CSF, IFN- $\gamma$, IP-10, MCP-1, MIP-1 $\alpha$, MIP-1 $\beta$, PDGF-BB, RANTES, TNF- $\alpha$ and VEGF in blood plasma of 19 healthy individuals. All volunteers received a thorough medical examination, in which there were no diseases. Sexual distribution of volunteers was- 10 women and 9 men, mean age was $30.4 \pm 8.3$ y.o.

Investigation of mRNA and chemokine receptors. The blood with the addition of EDTA, taken from the cubital vein, in $100 \mu \mathrm{L}$ was added in the Eppendorf tube. Added to $1400 \mu \mathrm{L}$ TE-buffer, stirred on the Vortex and left for incubation at room temperature for $3 \mathrm{~min}$. Then centrifuged for $1 \mathrm{~min}$. at $14,000 \mathrm{rpm}$, and then poured supernatant. The procedure for cleaning the TE buffer was repeated twice more. Next to the sediment was added $300 \mu \mathrm{L}$ lysing solution and incubated the tube at $65^{\circ} \mathrm{C}$ for $15 \mathrm{~min}$. Next was added $400 \mu \mathrm{L}$ of isopropanol and stirred sample at Vortex for 3 - 5 seconds. Tube was centrifuged at $14,000 \mathrm{rpm}$ for $5 \mathrm{~min}$. Supernatant were re- moved. Added to precipitate $500 \mathrm{~mL} \mathrm{70 \%} \mathrm{ethanol} \mathrm{so-}$ lution and gently turned over 3 - 5 times the tube. Tube was centrifuged at $14,000 \mathrm{rpm}$ for $5 \mathrm{~min}$. Supernatant were removed. Added to precipitate $500 \mu \mathrm{L}$ of acetone and 3 - 5 times gently turned over the tube and centrifuged it at $14,000 \mathrm{rpm}$ for $5 \mathrm{~min}$. Supernatant were removed. Opens the lid vials and dried sludge at $65^{\circ} \mathrm{C}$ for $10 \mathrm{~min}$. Added to precipitate $50 \mu \mathrm{L}$ DEPC-H2O and the sample was heated at $65^{\circ} \mathrm{C}$ for $5 \mathrm{~min}$. Reverse transcription was performed using a "Reverta" kit (Amplisens, Moscow, Russia) according to manufacturer's instructions.

The next step was the setting of PCR with specific primers (Table 1). Mode of PCR: $95^{\circ} \mathrm{C}-4 \mathrm{~min}, 30 \times$ $\left(95^{\circ} \mathrm{C}-30 \mathrm{~s}, 60^{\circ} \mathrm{C}-30 \mathrm{~s}, 72^{\circ} \mathrm{C}-30 \mathrm{~s}\right), 72^{\circ} \mathrm{C}-7 \mathrm{~min}$. As a house-keeping gene beta-actin was used. Visualization of the obtained PCR products was carried out in agarose gel under UV light. Semiquantitative evaluation was carried out using the program Gel-Pro, taking as $100 \%$ fluorescence intensity of beta-actin.

Multiplex cytokine detection. To determine the cytokine used equipment and reagents, Bio-Rad (Bio-Plex Suspension Array System). Use the standard panel of 27 cytokines. Blood plasma extracted from EDTA was added in wells. Continue to operate according to manufacturer's instructions.

Statistical data processing was performed using the software package STATISTICA 6.0 (used descriptive statistics, Spearman correlation analysis at a significance level $\mathrm{p}<0.05)$. Ethical Committee of I.P.Palov State Medical University approved the present study design.

Table 1. Primers are used.

\begin{tabular}{cccc}
\hline Name & Forward primer & Reverse primer & Amplicon length \\
\hline$\beta$-actin & CCAAGGCCAACCGCGAGAAGATGAC & AGGGTACATGGTGGTGCCGCCAGAC & 587 \\
eotaxin/CCL11 & ACCACCTCTCACGCCAAAGCTCACAC & CGGCACAGATATCCTTGGCCAGTTTG & 263 \\
eotaxin-2/CCL24 & CACATCATCCCTACGGGCTCT & GGTTGCCAGGATATCTCTGGACAGGG & 288 \\
IL-8/CXCL8 & GTGGCTCTCTTGGCAGCCTTCCTGAT & TCTCCACAACCCTCTGCACCCAGTTT & 253 \\
MIP-1 $\alpha$ CCL3 & GCCCGGTGTCATCTTCCTAACCAAGC & AGGGGACAGGGGAACTCTCAGAGCAA & 353 \\
MIP-1 $\beta /$ CCL4 & TGCTGCTTTTCTTACACCGCGAGGAA & AGAAGGGACAGGAACTGCGGAGAGGA & 291 \\
RANTES/CCL5 & CCCCGTGCCCACATCAAGGAGTATTT & CGTCCAGCCTGGGGAAGGTTTTTGTA & 316 \\
CCR1 & CAACTCCGTGCCAGAAGGTGAA & GCCAGGGCCCAAATGATGAT & 421 \\
CCR3 & GAGCCCGGACTGTCACTTTTG & CAGATGCTTGCTCCGCTCACAG & 410 \\
CCR5 & CTGGCCATCTCTGACCTGTTTTTC & CAGCCCTGTGCCTCTTCTTCTCAT & 487 \\
CXCR1 & GGCTGCTGGGGACTGTCTATGAAT & GCCCGGCCGATGTTGTTG & 383 \\
CXCR2 & CCGCCCCATGTGAACCAGAA & AGGGCCAGGAGCAAGGACAGAC & 427 \\
\hline
\end{tabular}


Informed consent of all volunteers to participate in the study was documented.

\section{RESULTS}

Table 2 shows the values of the amounts of cytokines in plasma. Table 3 shows the mRNA expression levels of chemokines and chemokine receptors in the blood of healthy volunteers. Eotaxin values in blood plasma was inversely interrelated with the level of expression of mRNA eotaxin-2 and MIP-1 $\alpha$. A positive relationship was observed between the eotaxin concentration and expression of mRNA IL-8. Correlations between the concentrations of cytokines and the level of mRNA eotaxin-2 are presented in Table 4. Expression of mRNA

Table 2. Cytokine values in plasma of healthy volunteers.

\begin{tabular}{|c|c|c|c|}
\hline Name & Median & $\mathrm{M}_{\min }$ & $\mathrm{M}_{\max }$ \\
\hline $\mathrm{IL}-1 \beta \mathrm{pg} / \mathrm{mL}$ & 0.1 & 0.0 & 1.0 \\
\hline IL-1 ra pg/mL & 67.0 & 0.0 & 207.3 \\
\hline IL-2 pg/mL & 0.9 & 0.0 & 5.0 \\
\hline IL-4 pg/mL & 0.7 & 0.0 & 9.0 \\
\hline IL-5 pg/mL & 0.1 & 0.0 & 2.4 \\
\hline IL-6 pg/mL & 2.3 & 1.1 & 8.2 \\
\hline IL-7 pg/mL & 2.3 & 0.0 & 8.7 \\
\hline IL-8 pg/mL & 0.5 & 0.0 & 4.6 \\
\hline IL-9 pg/mL & 0.0 & 0.0 & 8.9 \\
\hline IL-10 pg/mL & 0.5 & 0.0 & 2.9 \\
\hline IL-12(p70) pg/mL & 2.3 & 0.0 & 5.0 \\
\hline $\mathrm{IL}-13 \mathrm{pg} / \mathrm{mL}$ & 0.0 & 0.0 & 14.4 \\
\hline IL-15 pg/mL & 3.5 & 1.5 & 6.1 \\
\hline IL-17 pg/mL & 4.2 & 0.0 & 13.7 \\
\hline Eotaxin $\mathrm{pg} / \mathrm{mL}$ & 6.7 & 0.0 & 79.8 \\
\hline FGF-2 pg/mL & 9.3 & 0.0 & 55.6 \\
\hline G-CSF pg/mL & 9.6 & 0.0 & 21.1 \\
\hline GM-CSF pg/mL & 4.5 & 0.0 & 43.0 \\
\hline IFN- $\gamma$ pg/mL & 13.9 & 0.0 & 48.9 \\
\hline IP-10 pg/mL & 33.1 & 0.0 & 96.6 \\
\hline MCP-1 pg/mL & 0.1 & 0.0 & 0.2 \\
\hline $\mathrm{MIP}-1 \alpha \mathrm{pg} / \mathrm{mL}$ & 4.5 & 2.5 & 13.5 \\
\hline MIP- $1 \beta \mathrm{pg} / \mathrm{mL}$ & 10.9 & 0.0 & 42.2 \\
\hline PDGF-BB pg/mL & 507.1 & 0.0 & 5498.2 \\
\hline RANTES pg/mL & 154.1 & 141.3 & 2104.1 \\
\hline $\mathrm{TNF}-\alpha \mathrm{pg} / \mathrm{mL}$ & 6.5 & 2.1 & 39.5 \\
\hline VEGF pg/mL & 4.5 & 0.0 & 1296.5 \\
\hline
\end{tabular}

Table 3. Chemokine and chemokine receptor mRNA in whole blood of healthy volunteers, in percent respectively $\beta$-actin.

\begin{tabular}{lccc}
\hline \multicolumn{1}{c}{ Name } & Median & $\mathrm{M}_{\min }$ & $\mathrm{M}_{\max }$ \\
\hline Eotaxin & 2.7 & 0.6 & 10.4 \\
Eotaxin-2 & 2.8 & 0.3 & 14.3 \\
IL-8 & 1.1 & 0.0 & 9.1 \\
MCP-1 & 0.8 & 0.4 & 1.5 \\
MIP-1 $\alpha$ & 13.6 & 0.0 & 88.6 \\
MIP-1 $\beta$ & 1.2 & 0.0 & 11.3 \\
RANTES & 6.8 & 0.0 & 51.8 \\
CCR1 & 86.5 & 34.9 & 99.7 \\
CCR2 & 96.4 & 89.4 & 99.0 \\
CCR3 & 85.9 & 54.3 & 99.9 \\
CCR5 & 88.3 & 38.5 & 99.8 \\
CXCR 1 & 81.6 & 44.3 & 99.9 \\
CXCR 2 & 80.2 & 50.2 & 99.7 \\
\hline
\end{tabular}

Table 4. Correlations between cytokine values in plasma and eotaxin-2 mRNA expression in whole blood cells.

\begin{tabular}{|c|c|c|}
\hline Eotaxin-2 mRNA/cytokine & $\mathrm{r}$ & $\mathrm{p}$ \\
\hline IL-1 ra & -0.64 & 0.003 \\
\hline TNF- $\alpha$ & -0.46 & 0.045 \\
\hline IL-2 & -0.68 & 0.001 \\
\hline IL-7 & -0.78 & 0.000 \\
\hline IFN- $\gamma$ & -0.56 & 0.014 \\
\hline IL-4 & -0.60 & 0.006 \\
\hline IL-5 & -0.51 & 0.025 \\
\hline IL-9 & -0.46 & 0.048 \\
\hline IL-17 & -0.74 & 0.000 \\
\hline G-CSF & -0.71 & 0.001 \\
\hline FGF-2 & -0.48 & 0.038 \\
\hline PDGF-BB & -0.52 & 0.022 \\
\hline IL-10 & 0.55 & 0.014 \\
\hline Eotaxin & -0.60 & 0.006 \\
\hline IL-8 & -0.58 & 0.010 \\
\hline MCP-1 & -0.75 & 0.000 \\
\hline MIP- $1 \alpha$ & 0.68 & 0.001 \\
\hline RANTES & 0.71 & 0.001 \\
\hline
\end{tabular}


eotaxin-2 inversely correlated with levels of IL-8 and MCP-1. At the same time, the levels of eotaxin-2 mRNA were directly intertwined with the concentration of RANTES and MIP- $1 \alpha$. Expression of eotaxin- 2 mRNA was inversely related to the level of IL-1ra. In the present study found a negative correlation of expression of eotaxin- 2 mRNA and production of TNF- $\alpha$. We found that the level of eotaxin-2 mRNA was inversely related to the amount of IL-2 and IL-7 in the blood plasma. In our study, eotaxin-2 mRNA expression inversely correlated with the content of IFN- $\gamma$. We found that the level of eotaxin-2 mRNA is in inverse relationship with IL-4, IL-5, and IL-9. We explored that production of IL-17 appears back on the eotaxin-2 mRNA amount. In our study revealed that G-CSF production negatively affects the expression of eotaxin-2. This study showed that the FGF-2 and PDGF-BB plasma values negatively regulate eotaxin-2 mRNA level. We detected that the level of IL-10 and eotaxin-2 mRNA are in direct proportion.

In this study, the mRNA of IL- 8 directly correlated with the production of IL-8, eotaxin, MCP-1 and MIP- $1 \beta$ (Table 5). Expression of mRNA eotaxin-2 and MIP-1 $\alpha$ back depended on the concentration of IL-8. The direct relationship observed between the expression of the gene IL- 8 and the level of IL-1ra, TNF- $\alpha$, IFN- $\gamma$, IL-2, IL-4, IL-5 and IL-17 (Table 5).

Relationships between the contents of cytokines in plasma and the expression of MIP- $1 \alpha$ mRNA are presented in Table 6. We have identified a direct correlation between the levels of MIP- $1 \alpha$ mRNA and levels of MIP- $1 \alpha$ and RANTES. We found a negative correlation

Table 5. Correlations between cytokine values in plasma and mRNA expression of IL-8 in whole blood cells.

\begin{tabular}{ccc}
\hline IL-8 mRNA/cytokine & $\mathrm{r}$ & $\mathrm{p}$ \\
\hline IL-1ra & 0.76 & 0.000 \\
TNF- $\alpha$ & 0.48 & 0.039 \\
IL-2 & 0.74 & 0.000 \\
IFN- $\gamma$ & 0.51 & 0.027 \\
IL-4 & 0.55 & 0.015 \\
IL-5 & 0.58 & 0.009 \\
IL-17 & 0.48 & 0.036 \\
PDGF-BB & 0.71 & 0.001 \\
FGF-2 & 0.56 & 0.014 \\
eotaxin & 0.73 & 0.000 \\
MCP-1 & 0.47 & 0.042 \\
MIP-1 $\beta$ & 0.48 & 0.039 \\
IL-8 & 0.50 & 0.028 \\
\hline
\end{tabular}

Table 6. Correlations between cytokine values in plasma and mRNA expression of MIP- $1 \alpha$ in whole blood cells.

\begin{tabular}{ccc}
\hline MIP-1 $\alpha$ mRNA/cytokine & $\mathrm{r}$ & $\mathrm{p}$ \\
\hline IL-1ra & -0.85 & 0.000 \\
TNF- $\alpha$ & -0.61 & 0.005 \\
IFN- $\gamma$ & -0.72 & 0.001 \\
IL-2 & -0.79 & 0.000 \\
IL-7 & -0.71 & 0.001 \\
IL-4 & -0.72 & 0.000 \\
IL-5 & -0.64 & 0.003 \\
G-CSF & -0.56 & 0.012 \\
FGF-2 & -0.65 & 0.002 \\
PDGF-BB & -0.73 & 0.000 \\
IL-8 & -0.72 & 0.001 \\
eotaxin & -0.81 & 0.000 \\
MCP-1 & -0.63 & 0.004 \\
MIP-1 $\alpha$ & 0.50 & 0.029 \\
RANTES & 0.48 & 0.037 \\
\hline
\end{tabular}

between the expression of the gene MIP-1 $\alpha$ and levels eotaxin, IL-8 and MCP-1. We found that the value of MIP-1 $\alpha$ mRNA was in inverse relationship with levels of IL-1ra, TNF- $\alpha$, IFN- $\gamma$, IL-2, IL-7, IL-4, IL-5, G-CSF, FGF-2 and PDGF-BB. The amount of IL-10 and MIP- $1 \alpha$ mRNA were directly dependent. In our study, the value of RANTES in the plasma directly combined with the expression of eotaxin- 2 and MIP- $1 \alpha$ mRNA, whereas the mRNA level of MIP- $1 \beta$ and RANTES concentrations were inversely proportional. CCR1 - receptor binds MIP$1 \alpha$ and RANTES. We found that mRNA level of CCR1 was directly dependent on the amount of MIP- $1 \alpha$ and RANTES. Eotaxin and MIP- $1 \beta$, according to our data, back reflected on gene expression in CCR1. The value of IL-10 positively correlated with expression of mRNA CCR1, whereas the synthesis of the gene CCR1 back depended on the concentration of IL-17. CCR3-receptor for eotaxin, eotaxin-2, and RANTES. We detected that levels of MIP- $1 \alpha$ and RANTES were in direct connection with the values of mRNA of CCR3, whereas expression of the CCR3 gene was in the negative, depending on the concentration of eotaxin and MIP- $1 \beta$. CCR5 - a receptor through the MIP- $1 \beta$ and RANTES act. We found that levels of IL-1ra, IL-2, IFN- $\gamma$, IL-4, IL-5, eotaxin, MIP-1 $\beta$ PDGF-BB and inversely correlated with gene expression of CCR5. CXCR1 and CXCR2-receptors $\mathrm{CXC}$-chemokine family, are the most prominent representative of which is IL-8. In our study, 
IFN- $\gamma$, IL-4, IL-6, IL-8 eotaxin, FGF-2 and GM-CSF has negative effects on CXCR1 and CXCR2 mRNA expression.

\section{DISCUSSION}

Chemokines represent a system based on the interaction of ligand and receptor. However, it is known that chemokine receptors interact with components of the extracellular matrix. Separation chemokines on the constitutive and inducible rather questionable from the standpoint of the mechanism of their action. GPCR family of receptors is essential for cell physiology, so the activity of chemokines may not be at a neutral level. In addition, producers and targets of chemokines are all body cells, and during the cell cycle in some way the system is activated G-proteins and the cell produces a chemokine, or is the object of his actions. The cells of the human body are constantly in touch with viruses and bacteria resident microflora. Leukocytes interacting with bacterial and viral antigens provide adequate interaction with the microorganism microbiota. Chemokines are capable of reacting with cell membrane glycosaminoglycans, and chemokine receptors are activated by contact with the extracellular matrix. Both of these stimulate the induction of signaling pathways in target cells.

Eotaxin-2 is a chemokine responsible for the allergic inflammation due to prominent activity against eosinophils [3-5]. However, there is evidence for the fact that for the normal development of lungs in ontogenesis needed as eotaxin-2, and CCR3 [6]. Beck et al. [7] demonstrated that eotaxin-2 in vitro actively promotes the healing of artificial damage in the culture of the bronchial epithelium. Nigo et al. [8] found that the eotaxin-2 expression in the experiment after injection into mice of LPS increases TLR4-dependent manner. Rehani et al. [9] demonstrated that LPS-induced production of IL-1ra inhibited GSK3-signaling pathway. We can conclude that we have found a negative correlation between levels of IL-1ra mRNA and eotaxin-2 due to the negative effects of IL-1ra by GSK3 in TLR4-stimulated expression of eotaxin-2 mRNA. In our study, eotaxin plasma level inversely correlated with mRNA of eotaxin-2. Pope et al. [10] showed a different kinetics of mRNA expression eotaxin and eotaxin- 2 after ovalbumin sensitization of experimental animals, moreover, found that eotaxin and eotaxin-2 are expressed in different parts of the lungs. These differences, as well as what eotaxin and eotaxin-2 are encoded on different chromosomes may explain an inverse relationship between chemokine. We found an inverse correlation between the expression of mRNA eotaxin-2 and MCP-1 plasma value. This relationship may be explained by antagonism for CCR2 described Ogilvie et al. [11] for eotaxin and MCP-1. In our study demonstrated a negative feedback between eotaxin- 2 and IL-8, which is probably a consequence of antagonism between the CC and CXC-chemokine family, are confirmed we found inverse correlations between the content and expression eotaxin CXCR1 and CXCR2. Wong et al. [12] showed that under the influence of ligands of Tolllike receptors of eosinophils in vitro actively produce chemokines, including IL-8. Zhang et al. [13] emphasize that a combination of IL-2 and IL-4 increases the expression of CCR3 in the culture of B-lymphocytes isolated from germinal centers. The same study noted that eotaxin led to apoptosis of B-lymphocytes. Displayed in our study negative feedback between the expression of eotaxin-2 mRNA and IL-2 and IL-4 may be explained cross-regulation between chemokines and cytokines. Yoshida et al. [14] observed that IL-5 does not alter the expression of CCR3 and eotaxin-2 cell line NT93. We found that in healthy volunteers between the expression of eotaxin-2 mRNA and IL-5 production is a negative correlation, which can be attributed to suppressive influence of the Th2 immune response to eotaxin-2. Kelly et al. [15] established that IL-7 prevents apoptosis of eosinophils through autocrine induction of GM-CSF. According to our data eotaxin-2 mRNA is negatively dependent on IL-7. IL-9 is expressed together with its receptor in the airways in asthma [16]. Data on the presence and significance of IL-9 in healthy volunteers are not available. In our study, mRNA eotaxin-2 negatively interrelated with the concentration of IL-9, which may indicate the inhibiting role of the $\mathrm{Th} 2 \mathrm{immune}$ response to the expression of eotaxin-2. Cheung et al. [17] estimated that IL-17 produced by eosinophils, but also capable of inducing production of IL-8 and MIP- $1 \beta$. According to Rahman et al. [18] IL-17 stimulates the expression of eotaxin MAPK-dependent manner. In our study established a negative correlation between IL-17 production and eotaxin-2 mRNA expression, which indicates that the suppressive effect of Th17-type of immune response to eotaxin-2? Spencer et al. [19] observed that the eosinophils in vitro actively produce IFN- $\gamma$ and TNF- $\alpha$ in response to stimulation of ovalbumin. We revealed an inverse correlation between the expression of eotaxin-2 mRNA and IFN- $\gamma$ and TNF- $\alpha$ in plasma which demonstrates the overwhelming impact of Th1-type immune response to gene expression eotaxin-2 in healthy volunteers. We found a negative correlation between the eotaxin-2 mRNA expression and G-CSF, which, combined with the negative impact IL- 8 on eotaxin- 2 shows the inhibitory effect of the factors activate neutrophils in eosinophilic chemoattractant. We assessed that eotaxin-2 mRNA inversely correlated with the concentration of FGF-2 and PDGF-BB, indicating that the inhibitory effect of angiogenesis stimulators in the synthesis of chemokine mRNA. In our study established a direct cor- 
relation between the expression of IL- 8 mRNA and IL-1 ra, indicating that anti-inflammatory effect of IL-1ra, in response to the expression of IL-8 mRNA. We showed a positive correlation between the expression of the gene IL-8 and the concentration of IL-2. This observation may indicate that the components of the cell wall of normal microbiota via TLR-2 and TLR-5 induces production of IL-2 mRNA and IL-8. Allan et al. [20] shows that effector T-lymphocytes, after stimulation lipohexopeptide and flagellin-ligands, respectively, for TLR-2 and TLR-5, produce IL-2. McCarron and Reen [21] demonstrated the reinforcing effect of agonists of Toll-like receptors to produce IFN- $\gamma$ and TNF- $\alpha$ CD8-lymphocytes in vitro. We detected that IFN- $\gamma$ and TNF- $\alpha$ directly displayed on the mRNA expression of IL-8, this is possible due to stimulating signal after activation of Toll-like receptors. Mueller et al. [22] found that cultured epithelial cells of the intestine in the presence of IL- 4 and IL-13 is worse responsible products IL-8 in the induction of LPS, which is interpreted by the authors as the protective effect of Th2-cytokines on the excess activation of TLR4. In our study, however, IL-8 mRNA and IL-4 is a direct relationship, because of the system of local regulation of the activation process. Månsson and Cardell [23] studied response to stimulation of isolated eosinophils in vitro combination of TLR7 and TLR9 agonists in the presence or absence of IL-5. Adding IL-5 led to increased IL-8 production TLR-activated eosinophils. We found that production of IL-5 directly displayed on the IL-8 gene expression. As determined Nigo et al. [8], chemotactic activity of mast cells sensitized with ovalbumin, in respect of eosinophils increases lipopolysaccharide TLR4dependent manner. Based on data from Wong et al. [12], according to which, eosinophils under the influence of LPS produce IL-8, we can conclude that we have identified a direct correlation between the expression of mRNA IL-8 and the eotaxin is TLR4-dependent nature. Tomanek et al. [24] observed that FGF-2 and PDGF-BB in vitro accelerate the growth of coronary vessels. Faraone et al. [25] showed that FGF-2 and PDGF-BB co-regulate the growth of culture of umbilical vein endothelial cells. Petreaca et al. [26] showed that IL-8 increases angiogenesis, enhancing the permeability of the endothelium. According to our information there is positive correlation between the expression of mRNA IL-8 and both FGF-2 and PDGF-BB, which indicates the synergistic effect in vivo IL-8 and growth factors. IL-1 ra in our study was inversely proportional to the mRNA of MIP-1 $\alpha$, which is explained by anti-inflammatory effect of IL-1ra. In the experimental work of Ramos et al. [27] shows the multiplier effect of TNF- $\alpha$ on the migration of neutrophils stimulated by MIP- $1 \alpha$, in OVA-sensitized mice. We found a negative correlation between MIP- $1 \alpha$ mRNA and the concentration of TNF- $\alpha$, which indicates that the inhibitory effect of TNF- $\alpha$ on the synthesis of MIP-1 $\alpha$ mRNA in physiological conditions. Herd et al. [28] displayed in an experiment that mice infected with metapneumovirus in the lungs develops cytotoxic immune response with production of IFN- $\gamma$ and MIP- $1 \alpha$. In our study, gene expression, MIP- $1 \alpha$ back depended on the content of IFN- $\gamma$, which can be explained from competitive interactions between MIP- $1 \alpha$ and IFN- $\gamma$. Lerner et al. [29] studied experimentally response to various inducers of naive T-lymphocytes produce IL-2 and MIP$1 \alpha$. The work revealed that IL-2 production is maximal with stimulation of anti-CD3 antibody, whereas the concentration of MIP- $1 \alpha$ was highest after the addition of the culture of antigen-presenting cells. We found that production of IL-2 inversely correlated with the amount of mRNA of MIP-1 $\alpha$, which is a consequence of the participation of specific immune response in the suppression of gene expression in MIP- $1 \alpha$. We found that IL-7 was inversely related to gene expression in MIP-1 $\alpha$, which apparently characterizes the Th1-type as a negative regulator of MIP-1 $\alpha$. According to our data, mRNA expression of MIP-1 $\alpha$ inversely correlated with the level of IL-4 and IL-5. We can conclude that the Th2-response inhibit MIP-1 $\alpha$. We have demonstrated that MIP- $1 \alpha$ gene expression negatively correlated with the concentration of G-CSF, PDGF-BB and FGF-2, which can be interpreted as restraining influence angiogenesis activators on MIP- $1 \alpha$.

RANTES, in this study, directly displayed on the eotaxin-2 mRNA expression, which is probably due to activation of the receptor CCR3-shared for the two chemokine.

In studying the relationship of expression of mRNA chemokine receptor is important to consider the effects of redundancy and overlapping functions in the chemokine receptor. We found that CCR 1 gene expression is directly dependent on MIP- $1 \alpha$, RANTES and IL-10, which is explained by the direct action of the ligand to the receptor, and in the case of IL-10 regulation of the inflammatory response is likely. Expression of eotaxin and MIP- $1 \beta$ mRNA inversely related to CCR 1 mRNA, indicating a competitive relationship with the expression of chemokines and their receptors. The value of IL-17 in our study negatively correlated with the expression of the gene CCR1, which is a consequence of the suppressor effect of Th17-type immune response to the synthesis of mRNA receptor. CCR3 mRNA expression was directly related to the concentration of MIP- $1 \alpha$ and RANTES, whereas the eotaxin mRNA and MIP- $1 \beta$ adversely appearing on gene expression CCR3. As CCR5, then we have identified a negative relationship between the IL-1 ra, IL-2, IFN- $\gamma$, IL-4, IL-5, eotaxin, MIP-1 $\beta$ and PDGF-BB and CCR5 gene expression, which indicates the diversity inhibitors CCR5 mRNA in healthy volun- 
teers. CXCR1 mRNA was inversely proportional to IFN- $\gamma$, IL-4, IL-5, IL-6, IL-8, eotaxin, MIP-1 $\beta$, FGF-2, GMCSF and PDGF-BB, which is explained by redundancy of regulatory mechanisms gene expression in CXCR1. CXCR2 mRNA was inversely interrelated IFN- $\gamma$, IL-15, IL-4, IL-6, IL-8, FGF-2, GM-CSF and VEGF, which can be interpreted as heterogeneity of inhibitory influences on the activity of mRNA CXCR2.

\section{CONCLUSION}

Thus, the mRNA expression of chemokines and chemokine production in vivo is regulated by a wide range of cytokines, furthermore the activity of chemokine mRNA is able to be suppressed or induced by many ways under physiological conditions. Altogether, in healthy volunteers, there are mechanisms to maintain a balance of inductive and inhibitory stimuli (in our case, chemokines), which leads to adequate interaction with the microbiota and environment.

\section{REFERENCES}

[1] $\mathrm{Hu}, \mathrm{Z}$. (2009) Insight into microRNA regulation by analyzing the characteristics of their targets in humans. BMC Genomics, 10, 594.

http://www.biomedcentral.com/content/pdf/1471-2164-1

0-594.pdf

doi:10.1186/1471-2164-10-594

[2] Perry, M.M., Moschos, S.A., Williams, A.E., Shepherd, N.J., Larner-Svensson, H.M. and Lindsay, M.A. (2008) Rapid changes in microRNA-146a expression negatively regulate the IL- $1 \beta$-induced inflammatory response in human lung alveolar epithelial cells. Journal of Immunology, 180, 5689-5698.

[3] Pope, S.M., Fulkerson, P.C., Blanchard, C., Akei, H.S., Nikolaidis, N.M., Zimmermann, N., Molkentin, J.D. and Rothenberg, M.E. (2005) Identification of a cooperative mechanism involving interleukin-13 and eotaxin-2 in experimental allergic lung inflammation. Journal of Biological Chemistry, 280, 13952-13961. doi:10.1074/jbc.M406037200

[4] Scheicher, M.E., Teixeira, M.M., Cunha, F.Q., Teixeira Jr., A.L., Filho, J.T. and Vianna E.O. (2007) Eotaxin-2 in sputum cell culture to evaluate asthma inflammation. European Respiratory Journal, 29, 3489-3495. doi:10.1183/09031936.00060205

[5] Ochkur, S.I., Jacobsen, E.A., Protheroe, C.A., Biechele, T.L., Pero, R.S., McGarry, M.P., Wang, H., O’Neill, K.R., Colbert, D.C., Colby, T.V., Shen, H., Blackburn, M.R., Irvin, C.C., Lee, J.J. and Lee, N.A. (2007) Coexpression of IL-5 and eotaxin-2 in mice creates an eosinophil-dependent model of respiratory inflammation with characteristics of severe asthma. Journal of Immunology, 178, 7879-7889.

[6] Haley, K.J., Sunday, M.E., Porrata, Y., Kelley, C., Twomey, A., Shahsafaei, A., Galper, B., Sonna, L.A. and Lilly, C.M. (2008) Ontogeny of the eotaxins in human lung.
American Journal of Physiology-Lung Cellular and Molecular Physiology, 294, L214-L224.

doi:10.1152/ajplung.00086.2007

[7] Beck, L.A., Tancowny, B., Brummet, M.E., Asaki, S.Y., Curry, S.L., Penno, M.B., Foster, M., Bahl, A. and Stellato, C. (2006) Functional analysis of the chemokine receptor CCR3 on airway epithelial cells. Journal of Immunology, 177, 3344-3354.

[8] Nigo, Y.I., Yamashita, M., Hirahara, K., Shinnakasu, R., Inami, M., Kimura, M., Hasegawa, A., Kohno, Y. and Nakayama, T. (2006) Regulation of allergic airway inflammation through Toll-like receptor 4-mediated modification of mast cell function. Proceedings of the $\mathrm{Na}$ tional Academy of Sciences of the United States of America, 103, 2286-2291. doi:10.1073/pnas.0510685103

[9] Rehani, K., Wang, H., Garcia, C.A., Kinane, D.F. and Martin, M. (2009) Toll-like receptor-mediated production of IL-1Ra is negatively regulated by GSK3 via the MAPK ERK1/2. Journal of Immunology, 182, 547-553.

[10] Pope, S.M., Zimmermann, N., Stringer, K.F., Karow, M.L., Rothenberg, M.E. (2005) The eotaxin chemokines and CCR3 are fundamental regulators of allergen-induced pulmonary eosinophilia. Journal of Immunology, 175, 53415350 .

[11] Ogilvie, P., Thelen, S., Moepps, B., Gierschik, P., da Silva Campos, A.C., Baggiolini, M. and Thelen, M. (2004) Unusual chemokine receptor antagonism involving a mitogen-activated protein kinase pathway. Journal of Immunology, 172, 6715-6722.

[12] Wong, C.K., Cheung, P.F.Y., Ip, W.K. and Lam, C.W.K. (2007) Intracellular signaling mechanisms regulating Toll-like receptor-mediated activation of eosinophils. American Journal of Respiratory Cell and Molecular Biology, 37, 85-96. doi:10.1165/rcmb.2006-0457OC

[13] Zhang, Q.-P., Xie, L.-K., Zhang, L.-J. and Tan, J.-Q. (2005) Apoptosis in human germinal centre B cells by means of CC chemokine receptor 3 expression induced by interleukin-2 and interleukin-4. Chinese Medical Journal, 118, 665-670.

[14] Yoshida, N., Aizu-Yokota, E., Sonoda, Y., Moriwaki, Y., Kishi, K. and Kasahara, T. (2007) Production and regulation of eotaxin-2/CCL24 in a differentiated human leukemic cell line, HT93. Biological Pharmaceutical Bulletin, 30, 1826-1832. doi:10.1248/bpb.30.1826

[15] Kelly, E.A.B., Koziol-White, C.J., Clay, K.J., Lin, Y.L., Bates, M.E., Bertics, P.J. and Jarjour, N.N. (2009) Potential contribution of IL-7 to allergen-induced eosinophilic airway inflammation in asthma. Journal of Immunology, 182, 1404-1410.

[16] Shimbara, A., Christodoulopoulos, P., Soussi-Gounni, A., Olivenstein, R., Nakamura, Y., Levitt, R., Nicolaides, N., Holroyd, K., Tsicopoulos, A., Lafitte, J., Wallaert, B. and Hamid, Q.A. (2000) IL-9 and its receptor in allergic and nonallergic lung disease: Increased expression in asthma. Journal of Allergy and Clinical Immunology, 105, 108115. doi:10.1016/S0091-6749(00)90185-4

[17] Cheung, P.F.Y., Wong, C.K. and Lam, C.W.K. (2008) Molecular mechanisms of cytokine and chemokine release from eosinophils activated by IL-17A, IL-17F, and 
IL-23: Implication for Th17 lymphocytes-mediated allergic inflammation. Journal of Immunology, 180, 56255635.

[18] Rahman, M.S., Yamasaki, A., Yang, J., Shan, L., Halayko, A.J. and Gounni, A.S. (2006) IL-17A induces eotaxin-1/CC chemokine ligand 11 expression in human airway smooth muscle cells: role of MAPK (Erk1/2, JNK, and p38) pathways. Journal of Immunology, 177, 40644071.

[19] Spencer, L.A., Szela, C.T., Perez, S.A.C., Kirchhoffer, C.L., Neves, J.S., Radke, A.L. and Weller, P.F. (2009) Human eosinophils constitutively express multiple Th1, $\mathrm{Th} 2$, and immunoregulatory cytokines that are secreted rapidly and differentially. Journal of Leukocyte Biology, 85, 117-123. doi:10.1189/jlb.0108058

[20] Allan, S.E., Crome, S.Q., Crellin, N.K., Passerini, L., Steiner, T.S., Bacchetta, R., Roncarolo, M.G. and Levings, M.K. (2007) Activation-induced FOXP3 in human $\mathrm{T}$ effector cells does not suppress proliferation or cytokine production. International Immunology, 19, 345-354. doi:10.1093/intimm/dxm014

[21] McCarron, M. and Reen, D.J. (2009) Activated human neonatal $\mathrm{CD}^{+} \mathrm{T}$ cells are subject to immunomodulation by direct TLR2 or TLR5 stimulation. Journal of Immunology, 182, 55-62.

[22] Mueller, T., Terada, T., Rosenberg, I.M., Shibolet, O. and Podolsky, D.K. (2006) Th2 cytokines down-regulate TLR expression and function in human intestinal epithelial cells. Journal of Immunology, 176, 5805-5814.

[23] Månsson, A. and Cardell, L.-O. (2009) Role of atopic status in Toll-like receptor (TLR)7- and TLR9-mediated activation of human eosinophils. Journal of Leukocyte Biology, 85, 719-727. doi:10.1189/jlb.0808494
[24] Tomanek, R.J., Hansen, H.K. and Christensen, L.P. (2008) Temporally expressed PDGF and FGF-2 regulate embryonic coronary artery formation and growth. Arteriosclerosis, Thrombosis, and Vascular Biology, 28, 12371243. doi:10.1161/ATVBAHA.108.166454

[25] Faraone, D., Aguzzi, M.S., Ragone, G., Russo, K., Capogrossi, M.C. and Facchiano, A. (2006) Heterodimerization of FGF-receptor 1 and PDGF-receptor- $\alpha$ : A novel mechanism underlying the inhibitory effect of PDGF-BB on FGF-2 in human cells. Blood, 107, 1896-1902. doi:10.1182/blood-2005-04-1524

[26] Petreaca, M.L., Yao, M., Liu, Y., DeFea, K. and Martins-Green, M. (2007) Transactivation of vascular endothelial growth factor receptor-2 by interleukin-8 (IL-8/ CXCL8) is required for IL-8/CXCL8-induced endothelial permeability. Molecular Biology of the Cell, 18, 50145023. doi:10.1091/mbc.E07-01-0004

[27] Ramos, C.D.L., Canetti, C., Souto, J.T., Silva, J.S., Hogaboam, C.M., Ferreira, S.H. and Cunha, F.Q. (2005) MIP-1 $\alpha$ (CCL3) acting on the CCR1 receptor mediates neutrophil migration in immune inflammation via sequential release of TNF- $\alpha$ and $\mathrm{LTB}_{4}$. Journal of Leukocyte Biology, 78, 167-177. doi:10.1189/jlb.0404237

[28] Herd, K.A., Nelson, M., Mahalingam, S. and Tindle, R.W.J. (2010) Pulmonary infection of mice with human metapneumovirus induces local cytotoxic T-cell and immunoregulatory cytokine responses similar to those seen with human respiratory syncytial virus. Journal of General Virology, 91, 1302-1310. doi:10.1099/vir.0.015396-0

[29] Lerner, C.G., Horton, M.R., Schwartz, R.H. and Powell, J.D. (2000) Distinct requirements for C-C chemokine and IL-2 production by naive, previously activated, and anergic T cells. Journal of Immunology, 164, 3996-4002. 